Monatsschrift f. Geburtshülfe u. Gynäkologie 1920;51:63

\title{
Die Jahrhundertteier der Dresdener Frauenklinik
}

\section{A. Martin}

Dezember 1920 unter zahlreicher Beteiligung der Behörden und weitester ärztlicher Kreise von dem zum Geheimen Medizinalrat ernannten derzeitigen Leiter E. Kehrer mit einer Festrede begangen worden, welche die Entwioklungsgeschichte dieses zu so hoher Be-deutung entwickelten Institutes schildert. Aus privater Wohltätigkeit 1792 von bescheidensten Verhältnissen (3 Betten für Sahwangere und Wöchnerinnen) hervorgegangen, wurde die Anstalt trotz der Bedräng-iiis der ersten Jahrzehnte bis 1813 durchgehalten. Nachdem sie infolge der Verluste der Freiheitskriege für fast 11i \&gt; Jahre hatte geschlossen werden müssen, wurde sie am 1. Dezember 1914 wieder ins Leben gerufen. 1903 ist sie von Leopold in das vonihm in bekannterGroßzügigkeit aus-gestattete jetzige Heim übergeführt $\Lambda$ vorden. Die den Namen ihrer Direktoren, C. G. Cams, Fr. Haase, W. L. Grenser, Fr. v. Winckel und Oil. G. Leopold, gewidmete Festschrift erscheint im Rahmen des Archiv für Gynäkologie. Mit vollem Recht hebt Kehrer hervor, daß diese Manner, mit Ausnahme Haases der wohl dutch seinen eignen Leidenszustand behindertwar, als Führer ihrer Zeit gewiAt und gegoltenhaben. Auch heute nochgiltuns ÄlterenGVeÄsef als derHerausgeber.derpostumen Auflagen des seinerzeit $\mathrm{f}$ ührenden geburtshiilflichen Lehrbuches Naegeles. Winckel verdanken wir weitgehend die so nachhaltige Entwicklung der geburtshiilf lichen Ausbildung der Ärzte im nachklinischen Studium: er machte aus der Hebammenschule die geburtshülflich-gjmäkologische Kiinik modernen Stils. Leopold hat auf dieser Grundlage überaus erfolg-reich weiter gebaut. Seine Gestalt. sein Wirken und Schaffen stehen uns alien heute noch in frischer Erinnerung. E. Kehrer führt die Kiinik seit dem 1. November 1911. nachdem er das Ordinariat in Bern auf-gegeben. Trotz der schweren Bedrängnis, welche die Kriegsjahre auch der Dresdener Frauenklinik gebracht haben, ist es ihm gelungen, den Betrieb clurchzuhalten und besonders \&lt; len sich häufenden pathologischen Geburtsfällen gerecht zu werden. Die Sakralanästhesie, die subkutane Sympliyseotomie, die Ausbildung der Fürsorge für frühgeborene Kinder und dieBekämpfung desKarzinoms durch die Radmmtherapie bedtuten Etappen auf Kehrers Arbeit in der Dresdner Frauenklinik.

Wir halten uns der freudigen Zustimmung der Gesamtheit unsercr Leser vorsichert, wenn wir Herrn Kollegen Kehrer lebhaft zu seinen bisherigen Erfolgen beglückwünschen und die zuversichthche Hoffnung aussprechen, daß ihm in noch langjähriger ïätigkeit an der Spitze dieter Kiinik eine Fülle weiterer winken zu Nutzen und Frommen der Wissenschaft und seines Institute, zu seiner $\mathrm{e}^{1 / 8} / \mathrm{enen}$ vollen Befriedigung! A. Martin. 